Published in: International Encyclopedia of the Social and Behavioral Sciences (Vol. 6, pp. 3684-3688). Amsterdam: Elsevier.

(C) 2001 Elsevier Science.

\title{
Digital Computer: Impact on the Social Sciences
}

\author{
Gerd Gigerenzer \\ Max Planck Institute for Human Development, Berlin, Germany
}

The invention of the computer has been described as the third information revolution-after the advent of writing and the printing press. Computers transformed our world, in reality and fiction: from online library catalogues and the World Wide Web to the vision of machines that will eventually surpass humans in intelligence and even replace us by self-replicating computers divorced from biological evolution. This revolution was difficult to foretell. Howard Aiken, the Harvard mathematician and builder of the Mark I calculator, predicted in 1948 that there would be no commercial market for electronic computers; he estimated that the USA would need only five or six such machines, but no more. As early as the 1960s, electrical engineer Douglas Carl Engelbart had designed the first interactive computer tools, including the mouse, on-screen editing, screen windows, hypertext, and electronic mail. However, at this time, human-computer interaction still seemed science fiction—computers were for processing punched cards, not for interacting with humans. The impact computers had on society and science was difficult to imagine, and we may be in the same position with respect to the future.

The impact goes in both directions: computers and humans coevolve. This coevolution is illustrated by the work of Charles Babbage (1791-1871), the English mathematician who is often credited with the invention of the digital computer.

\section{The Computer as a Factory of Workers}

Babbage's Analytical Engine, a mechanical computer, was inspired by and modeled on a new social organization of work: the large-scale division of labor, as evidenced in the English machinetool industry and in the French government's manufacturing of logarithmic and trigonometric tables for the new decimal system in the 1790s. Inspired by Adam Smith's praise of the division of labor, French engineer Prony organized the project in a hierarchy of tasks. At the top were a handful of first-rank mathematicians, including Adrien Legendre and Lazare Carnot, who devised the formulae; in the middle, seven or eight persons trained in analysis; and at the bottom, 70 or 80 unskilled persons who performed millions of additions and subtractions.

Once it was shown that elaborate calculations could be carried out by an assemblage of unskilled workers—rather than by a genius such as Gauss—each knowing very little about the larger computation, it became possible for Babbage to conceive of replacing these workers with machinery. Babbage, an enthusiastic "factory tourist," explicitly referred to this division of mental labor as the inspiration for his mechanical computer, and he used terms from the textile industry, such as "mill" and "store" to talk about its parts. Similarly, he borrowed the use of punched cards from the Jacquard loom, the programmable weaving machines that used removable cards to weave different patterns. Thus, in the beginning there was a new social system of work, and the computer was created in its image. 


\section{The Hierarchical Organization of the Mind}

Babbage's Analytical Engine was never completed. Around 1890, the first "digital calculators" were manufactured, so named because they represented numbers by cogged wheels whose positions corresponded to the digits in the numbers denoted. (An abacus was still cheaper and faster.) Analog computers, in contrast, are devices in which continuous quantities, such as electrical potential or mechanical motion, are used instead of discrete (e.g., on/off) states. Until the first third of the twentieth century, digital calculators remained essentially mechanical. In the late 1930s, electromechanical relay switches started replacing gears and cogs in calculators. The electronic computer based on vacuum tubes and containing no movable parts appeared during World War II and was invented three times: in Germany for airplane design, in the USA for calculating artillery tables, and in the UK for breaking German secret codes. Vacuum tubes were eventually replaced by transistors, and finally by silicone chips, which allowed the transition from large mainframes to minicomputers. The first personal computers - complete with keyboard, screen, disk drive, and software-were marketed by Apple in 1977, and by IBM in 1981.

Through these dramatic improvements in hardware and speed, Smith's ideal of the division of labor became the basis for a fresh understanding of the human mind. Herbert Simon and Allan Newell proposed that human thought and problem solving were to be understood as a hierarchical organization of processes, with subroutines, stores, and intermediate goal states that decomposed a complex problem into simple tasks. In fact, a social system rather than a computer performed the trial run for the Logic Theorist, their first computer program. Simon's wife, children, and graduate students were assembled in a room, and each of them became a subroutine of the program, handling and storing information. This was the same as the nineteenth-century French "bureaux de calculs" and the Manhattan project, where calculations were done by an unskilled workforce-mostly women, at low pay. Similarly, Marvin Minsky, one of the founders of artificial intelligence, regarded the mind as a society of dumb agents, collectively creating true intelligence. Similarly, anthropologists have begun to use computer analogies to understand how social groups make decisions, such as how the crew on a large ship solves the problem of navigation by storing, processing, and exchanging information. The direction of the analogy thus eventually became reversed: originally, the computer was modeled on a new social system of work; now social systems of work are modeled on the computer.

\section{From Calculation to Computation}

A crucial insight occurred when the early designers of computers realized that a computer could be used not only for calculation but more generally for symbol processing. The switch positions inside the machine could take on other meanings than numbers; they could stand for symbols representing concepts. This insight fueled the view of cognition as computation, that is, symbol manipulation. A computer that merely performed fancy calculations would not have suggested itself as a model of human thought. During the Enlightenment, proficient calculation indeed was seen as the essence of intelligence and even moral sentiment, but after the introduction of the large-scale division of labor around 1800, prodigious mental reckoning had became the mark of the idiot savant rather than the genius.

The notion of computation led to two questions: Can computers think? Is human thought computation? To avoid endless philosophical debate on exactly how to define the first question, Alan Turing (1912-1954) suggested the "imitation game," now known as the Turing test: 
A human interrogator must distinguish between a computer and a human subject based on their replies to the interrogator's questions. In a series of such experiments, a computer's ability to think could be quantified as the proportion of interrogators who misidentify the machine as the human subject. Turing asked whether the computer is like a mind: whether it thinks, has free will, and whether one can teach machines to become intelligent using the same psychological principles used to teach children. Those who focused on the second question - is the mind like a computer? - saw the analogy pointing in the other direction. For instance, they tried to teach children using the same principles that had worked for computers. This analogy of the mind as computer fueled the cognitive revolution in psychology during the 1960s and 1970s.

The "physical symbol system" hypothesis proposed by Simon and other researchers in artificial intelligence assumes that human cognition is computation in the sense of symbol manipulation. According to this view, symbols represent the external world; thought consists of expanding, breaking up, and reforming symbol structures, and intelligence is nothing more than the ability to process symbols. Information processing became the key to understanding human thought, and the tools of programming provided the mechanisms of thought: production systems, subroutines, recursion, iteration statements, local naming, interpreters, and so on. This view was not easily reconcilable with prevailing theories of thought, from Freud's theory of mind as manipulating biological energies, to the behaviorists' view that thought is simply silent speech, or to the Gestalt psychologists' view emphasizing the context dependency, interconnectedness, and emergent quality of thought. In essence, the vision of cognition as symbol manipulation revived the Enlightenment view of thought as a combinatorial calculus. For Condillac, d'Alembert, Condorcet, and other Enlightenment philosophers, the healthy mind worked by constantly breaking down ideas and sensations into their minimal elements, then comparing and rearranging these elements into novel combinations and permutations.

The view of thought as symbol manipulation also revived the old dream of a logic of scientific discovery, the existence of which Karl Popper had so vehemently disclaimed. Computer programs such as BACON managed to infer scientific laws from data, and artistic creativity was modeled on the same combinatorial principles. Computer programs were written that composed music, wrote stories, and designed new Palladian villas and prairie houses. Leibniz's dream of a Universal Characteristic that would assign to each concept a number, and reduce each problem to calculation, seemed to have come true. Like Babbage and Pascal, Leibniz had designed one of the first computers.

Through the medium of the computer, the Enlightenment psychology re-entered modern psychology. This is, however, only half the story. Just as George Boole had set out in the midnineteenth century to derive the laws of logic and probability from the psychological laws of human thought, researchers such as Simon and Newell tried to enter into their computer programs the results of psychological research about human thought. For instance, the concept of heuristics that speed up search in a problem space proved to be essential for intelligent programs. Heuristics are smart rules of thumb that humans apply in everyday reasoning when optimization, such as maximizing expected utility, is impossible or would cost too much time (see Decision Making: Nonrational Theories).

The metaphor of the mind as computer must be distinguished from John von Neumann's (1903-1957) metaphor of the brain as computer. Von Neumann, known as the father of the modern computer, was concerned with similarities between the nervous system and computer, neuron and vacuum tube- but added cautionary notes on their differences. Turing, in contrast, thought the observation that both the modern digital computer and the human nervous system are electrical was based on a superficial similarity. He pointed out that the first digital computer, 
Babbage's Analytical Engine, was mechanical rather than electrical, and that the important similarities to the mind are in function rather than in hardware.

How quickly did the metaphor of the mind as computer come to be accepted by cognitive psychologists? Consistent with the tools-to-theories heuristic - which says that new scientific tools suggest new metaphors of mind, society, or nature but are accepted by a scientific community only after the members have become users of the tool-the broad acceptance of the mind as computer metaphor was delayed until the 1970s and 1980s, when personal computers became the indispensable tool of researchers. Before the advent of personal computers, researchers had little direct contact with the large mainframe computers, and for those who did, computers were a source of constant frustration. For instance, in an average week in 1965-1966, the PDP-4C computer of the Center for Cognitive Studies at Harvard saw 83 hours of use, but 56 of these were spent on debugging and maintenance. A 1966 technical report of the Center was entitled "Programmanship, or how to be one-up on a computer without actually ripping out its wires." The metaphor of the mind as computer only became widely accepted after the tool had become part of the daily routine in psychological laboratories.

\section{From Thought Experiments to Simulation}

Thought experiments, from physics to political science, have been a research tool in situations where no data could be obtained, such as counterfactual historical scenarios. The computer created a new species of thought experiments: computer simulation. Jay Forrester's Club of Rome world resource model — which predicted worldwide famine followed by war in the first third of the twenty-first century-is one of the best-known early social science simulations. Robert Axelrod's classic "prisoner's dilemma" computer tournament demonstrated the success of a simple social heuristic called tit-for-tat and became the model for numerous simulations on game theory, reciprocal altruism, and political science. Simulations force researchers to specify their theoretical ideas precisely, and they have become a tool for discovering new implications of these ideas. In some fields the need to specify assumptions precisely has become a requirement for what constitutes a theory: what cannot be simulated does not deserve to be called a theory.

Computer simulation allows the modeling of dynamic systems, such as the evolution of social structures through the repeated interaction between individuals. Computer simulation is a truly new form of experiment, but social scientists are divided over what role it should have in research. In artificial intelligence, organizational theory, and demography, for instance, simulation has a long tradition. In sociology, in contrast, simulation is still rare and little respected. Simulation tends to be rare in fields where a distinction (or even hostility) between theoretical and empirical research is deeply entrenched, such as sociology, and where computers are heavily used for the analysis of empirical data. Perceived as the instrument of the "other," number crunching camp, the computer's theoretical possibilities tend to be forgotten.

\section{A World of Numbers and Statistics}

When the statistician Karl Pearson assembled the famous Biometrika statistical tables between 1914 and 1934, he used a 50-lb Brunsviga calculator and numerous clerks. The 1946 ENIAC -which is commonly referred to as the first modern digital electronic computer using vacuum tubes—could calculate 5,000 additions per second, that is, it did the work of a whole factory of 
clerks. Fifty years later, a tiny and relatively inexpensive Pentium chip could conduct over 500 million operations per second. This explosion of calculating power together with decreasing cost and size has had a dramatic influence on the social sciences, both positive and negative. The emphasis has shifted from collecting qualitative observations to quantitative data, and from a priori theoretical thinking to the post hoc interpretation of significant correlations.

At the end of World War II, half of the articles in the American Sociological Review and American Journal of Sociology lacked any kind of quantitative mathematical analysis; thirty years later this number had decreased to about 13 percent. In psychology, as in sociology, the predominant quantitative methods before the advent of electronic computers were descriptive statistics, such as means, variances, percentages, correlations, and cross tabulations. With the advent of fast calculators, the social sciences have witnessed a rapid growth in the usage of computationally expensive statistical methods, including factor analysis, cluster analysis, analysis of variance, and multiple regression. The computer also provided tools that could make data structures visually transparent and help researchers see underlying structures—called exploratory data analysis. Sociologists, demographers, and anthropologists were finally able to analyze large samples in a short time, such as census data and voting polls.

Computerized statistical packages such as SPSS (Statistical Package for the Social Sciences) have not only helped but also have hurt progress. Their ease of application (e.g., compute "everything by all") has often replaced statistical thinking with statistical rituals. One widespread ritual is null hypothesis testing, in which the researcher mechanically tests whether data significantly deviates from a null hypotheses ("chance"), without ever specifying the predictions of the research hypothesis and of competing hypotheses, and without measuring effects and constructing substantive theories of some depth. As a consequence, researchers tend to skim through computer printouts looking not at the data but at the significance level of the correlations or chi-squares and engage in post hoc explanations for whatever comes out significant.

\section{Research and Teaching Assistance}

Next to data analysis, the most common use of computers in the social sciences is that of an efficient and patient research assistant. A computer can serve as a librarian who searches for relevant publications and historical records; as a data bank manager who stores and retrieves narrative information, qualitative and numerical data; as a secretary who edits and files texts, keeps track of footnotes and references; and as a fast electronic mail system that facilitates contacts with colleagues worldwide. In experimental psychology, computers run entire experiments with humans and animals; they present the experimental stimuli and record the participants' responses.

This interactive use of computers would not have been possible without the invention of the personal computer that replaced the large mainframes. Engelbart's invention of the mouse exemplifies how human abilities such as hand-eye coordination can be exploited to design appropriate tools with which humans can almost intuitively interact with computers. In social science teaching, human-computer interaction can increase the participation of all students, whereas in the traditional classroom small groups of students often tend to dominate the discussion. Chat rooms on the World Wide Web have become a new and cheap data source for anthropologists and psychologists. The Web in turn has generated legal and ethical problems concerning secrecy and data protection, motivating revisions of the copyright law, tax law, and criminal law. 


\section{The Computer Revolution}

Has the computer fundamentally changed the social sciences? As we have seen, the kind of impact differs across the social sciences. The invention of the modern computer has increased interdisciplinarity through the creation of cognitive science, consisting of artificial intelligence, psychology, philosophy, linguistics, anthropology, and neuroscience. However, sociology is notably absent from that list. Electronic mail and the Internet have made international collaboration easier and faster than ever. Simulation, expert systems, neural networks, and genetic algorithms would be unthinkable without high-speed computers, and so would be statistical analyses of large bodies of data. In these respects, the social sciences today have available a repertoire of powerful new tools and opportunities. Has the computer revolutionized our conception of mind and society? The answer seems to be yes if we use the original meaning of the term-a re-volution, that is, a return to earlier conceptions. The metaphor of the mind as computer, for instance, has brought back the combinatorial view of cognition of the Enlightenment and Adam Smith's ideal of a division of labor. Thinking, problem solving, creativity, and scientific discovery came to be explained by a hierarchically organized mind that decomposes complex problems into simpler subroutines. In this way, theories of mind and society that had existed before computers, were expanded and perfected.

See also: Computational Approaches to Model Evaluation; Computational Imagery; Computer Networking for Education; Computer-assisted Instruction; Computerized Test Construction; Computers and Society; Metaphor and its Role in Social Thought: History of the Concept; Pearson, Karl (1857-1936); Quantification in the History of the Social Sciences; Science and Technology, Social Study of: Computers and Information Technology; Social Simulation: Computational Approaches; Statistics, History of.

\section{Bibliography}

Ceruzzi, P. E. (1998). A history of modern computing. Cambridge, MA: MIT Press.

Collins, T. W. (1981). Social science research and the microcomputer. Sociological Methods \& Research, 9, 438460.

Crevier, D. (1992). AI: The tumultuous history of the search for artificial intelligence. New York: Basic Books.

Daston, L. (1994). Enlightenment calculations. Critical Inquiry, 21, 182-202.

Garson, G. D. (1994). Social science computer simulation: Its history, design, and future. Social Science Computer Review, 12, 55-82.

Gigerenzer, G. (1993). The superego, the ego, and the id in statistical reasoning. In G. Keren \& G. Lewis (Eds.), $A$ handbook for data analysis in the behavioral sciences: Methodological issues. Hillsdale, NJ: Erlbaum.

Gigerenzer, G., \& Goldstein, D. G. (1996). Mind as computer: The birth of a metaphor. Creativity Research Journal, 9, 131-144.

Langley, P., Simon, H. A., Bradshaw, G. L., \& Zytkow, J. M. (1987). Scientific discovery. Cambridge, MA: MIT Press.

McCorduck, P. (1979). Machines who think. San Francisco: Freeman.

Newell, A., \& Simon, H. A. (1972). Human problem solving. Englewood Cliffs, NJ: Prentice-Hall.

Schaffer, S. (1994). Babbage's intelligence: Calculating engines and the factory system. Critical Inquiry, 21, 203227.

Simon, H. A. (1969). The sciences of the artificial. Cambridge, MA: MIT Press.

Todd, P. M. (1996). The causes and effects of evolutionary simulation in the behavioral sciences. In R. Belew \& M. Mitchell (Eds.), Adaptive individuals in evolving populations (pp. 211-224). Reading, MA: AddisonWesley.

Turing, A. M. (1950). Computing machinery and intelligence. Mind, 59, 433-460. 